\title{
BMJ Open Perception of obesity and overweight among adults living in suburban Nepal: a qualitative study
}

\author{
Sachita Shrestha (10 ,1,2 Shanta Asthanee, ${ }^{1}$ Biraj Man Karmacharya, ${ }^{1,3}$ \\ Seema Subedi, ${ }^{4}$ Rajendra Koju ${ }^{5}$
}

To cite: Shrestha S, Asthanee S, Karmacharya BM, et al. Perception of obesity and overweight among adults living in suburban Nepal: a qualitative study. BMJ Open 2021;11:e043719. doi:10.1136/ bmjopen-2020-043719

- Prepublication history for this paper is available online. To view these files, please visit the journal online (http://dx.doi. org/10.1136/bmjopen-2020043719).

Received 13 August 2020 Revised 07 April 2021 Accepted 16 April 2021

Check for updates

(c) Author(s) (or their employer(s)) 2021. Re-use permitted under CC BY-NC. No commercial re-use. See rights and permissions. Published by BMJ.

${ }^{1}$ Department of Community Programmes, Dhulikhel Hospital, Dhulikhel, Kavrepalanchok, Nepal

${ }^{2}$ UNC Linberger Comprehensive Cancer Center, University of North Carolina at Chapel Hill School of Medicine, Chapel Hill, North Carolina, USA

${ }^{3}$ Department of Public Health, Kathmandu University School of Medical Sciences, Kathmandu,

Nepal

${ }^{4}$ Department of International Health, Johns Hopkins University, Baltimore, Maryland, USA

${ }^{5}$ Department of Cardiology, Dhulikhel Hospital, Dhulikhel, Kavrepalanchok, Nepal

Correspondence to

Sachita Shrestha;

sachizshrestha@gmail.com

\section{ABSTRACT}

Objective To explore the perception of obesity and overweight among Nepalese adults living in a suburban community.

Design A qualitative study composed of focus group discussion (FGD) and in-depth interview (IDI).

Setting Community and healthcare facilities in Dhulikhel, Nepal.

Participants Four FGDs were conducted with community members $(n=22)$ and four IDIs were conducted with healthcare providers (HCPs).

Results Obesity is a rising problem in this suburban community. Participants had inadequate knowledge regarding the consequences of obesity, and they perceived overweight as normal, healthy and attractive. The participants above 40 years of age did not perceive themselves to be overweight or obese. Despite participants' awareness of the importance of diet control and exercise to prevent obesity, these were not translated into practice.

Conclusions This study provided insight into perceptions of obesity in a suburban Dhulikhel community through both community members' and HCPs' perspective. Misconceptions and inadequate knowledge of obesity among people in this community indicate the need for health education and intervention programme to increase health awareness and preventive practices.

\section{BACKGROUND}

Obesity is one of the top five causes of cardiovascular mortality and morbidity globally ${ }^{1}$ causing an increased risk of coronary artery disease, diabetes mellitus, hypertension and kidney failure. ${ }^{2}$ The rate of obesity has increased in many developing nations, including Nepal. ${ }^{3-5}$ About $24.3 \%$ of Nepalese adults are obese or overweight. ${ }^{6}$

Several demographic, socioeconomic and cultural factors contributing to obesity have been described elsewhere. ${ }^{7-9}$ Like other developing countries, Nepal is undergoing epidemiologic and demographic transition, experiencing significant lifestyle changes. ${ }^{7-10}$ Urbanisation, leading to an increased number of fast-food restaurants, the growing culture of 'eating out', and the availability

\section{Strengths and limitations of this study}

To our knowledge, this is the first qualitative study in Nepal to explore the perception of obesity among adults in a suburban community in Nepal.

- The study includes in-depth views of both community members and healthcare providers working at different levels.

- The study is limited to the Dhulikhel Heart Study participants residing in a suburban area; therefore, the findings of the study may not be transferable to rural or urban areas.

- This study provides information on obesity and its perceived threat in a resource-poor setting.

- The study has generated recommendations and possible strategies for obesity and non-communicable disease (NCD) prevention in the vulnerable population in Nepal.

of lower-priced, higher caloric food have contributed to obesity. The 2019 WHO STEPS (STEPwise approach to surveillance) survey reported low physical activity and low vegetable and fruit consumption in Nepal. ${ }^{6}$

Studies have found a relationship between obesity and body weight/size perception. Unlike in developed countries, a heavier body is preferred in many developing countries, such as South Africa and Tanzania. ${ }^{811}$ In Nepal, traditionally, having a 'big belly' is considered a sign of prosperity. ${ }^{7}$ This perceived norm might be facilitating weight gain, particularly among high-income individuals and families. However, with epidemiologic transitions and technological advancements occurring globally, this perception may be changing. It is also important to understand how the individual perceives their body size. The individuals who do not see themselves as overweight/obese are prone to gain weight because of their low-risk perception and unwillingness to lose weight. ${ }^{811} 12$ On the other hand, women generally misperceive body weight, deeming it higher than it 
is, and thus are dissatisfied with their bodies compared with men. ${ }^{13}$

In 2015, the Dhulikhel Heart Study (DHS), a population-based cohort study on cardiovascular disease and its risk factors, was conducted among adults living in Dhulikhel, a suburban town in Nepal. ${ }^{14}$ The study found a high prevalence of cardiovascular disease and its risk factors, such as obesity. Given the high prevalence of obesity and poor cardiovascular health literacy, the development of effective health education and intervention programmes to manage obesity in this community is vital. Although studies regarding obesity perception have been conducted in many low-income and middleincome countries (LMICs), ${ }^{815-17}$ information on body size self-perception and willingness to lose weight among Nepalese adults is limited. In 2009, Simkhada $e t$ al conducted a cross-sectional study to assess knowledge, attitude and prevalence of overweight and obesity among civil servants in Nepal. ${ }^{18}$ Few qualitative studies that have been conducted in this context focus primarily on diet and exercise. ${ }^{19} 20$ To our understanding, there are no qualitative studies conducted to date exploring body size perception and willingness to lose weight among adults in Nepal. Also, no studies exist to understand obesity from the healthcare provider (HCP)'s perspective in Nepal. Our study aims to fulfil the above-mentioned gaps in knowledge by exploring the perception of obesity and overweight among Nepalese adults, including both community members and HCPs.

\section{METHODS}

\section{Study design and setting}

This was a qualitative study under a large cohort study, the DHS, which is a longitudinal cohort study conducted between November 2013 and February 2015 to assess the prevalence of cardiovascular diseases and its risk factors among adults of 18 years and older living in Dhulikhel, a suburban town in Nepal. ${ }^{14}$

\section{Participants}

We conducted four focus group discussions (FGDs) with 22 DHS participants. We used FGDs for community members as this method is proven to adequately gather information on the perception of obesity among adults in LMICs. ${ }^{815}$ Participants were selected using purposeful sampling methods. A list of DHS participants was obtained and stratified into four groups by gender (male and female) and age ( $<40$ and $\geq 40$ years). The separation of gender was necessary because women in Nepalese culture are usually shy and do not discuss explicitly in the presence of men. The researcher contacted 12 eligible participants from each group via phone call to request participation in the study. Participants who provided verbal consent were invited for discussions. Of the total 48 eligible participants who agreed to participate, 22 took part in the group discussions. Six participants who initially agreed to participate did not attend the discussion.
Altogether 26 eligible participants did not participate in the study. The reasons for non-participation were busy schedules on the given time and date and medical illness.

For the in-depth interview (IDI), we purposefully selected four health providers (HPs) from different healthcare levels to explore barriers to obesity management. We selected one doctor and a nutritionist from the tertiary hospital, an in-charge from a primary healthcare centre and an in-charge from an urban healthcare centre. All HCPs who were invited agreed to participate in the study and were interviewed.

\section{Data collection}

We collected data from October 2016 to December 2016. We developed initial guidelines in Nepali. The FGD guideline was pilot tested among six DHS participants, and the IDI guideline was pretested with a doctor in the tertiary hospital. The guidelines were then reviewed and modified accordingly. The findings from the pretested FGD and IDI were not included in this analysis.

All FGDs were moderated by the researcher and assisted by a note-taker. The moderator was not from the study community and, hence, had no prior knowledge about the participants before the study. The moderator started each session by briefly explaining the aim of the study and receiving informed consent. Participants' height and weight were also measured before the discussion started. The moderator started the discussion with open-ended questions and probed further for in-depth information. The FGD guideline included 10-item questions under four topics-body size perception; knowledge on obesity; attitude towards obesity; and barriers to weight management. For the perception of body size, we asked participants' views on their body size and then probed why they think their body is normal or overweight or obese and how they measure their body size. To explore participants' knowledge of obesity, we asked questions on the perceived cause and complications of obesity and further probed if certain groups in the community are perceived as more obese than others. On attitude towards obesity, we asked the following questions, 'How do you view overweight and obesity?', and 'What influences society's views on obesity?' Regarding the willingness to lose weight or maintain optimally, we asked about the perceived barriers to weight management. We conducted FGDs in a private space at a community building. The group size varied from three to seven. FGD participants were offered a light snack for their time and participation.

The investigator (SA) conducted IDIs with HCPs in the private room at their respective healthcare centres. Informed consent was received before each interview. The IDIs were conducted to understand the burden of obesity in the community, providers' perspectives on the community's knowledge and attitude on obesity, and providers' related barriers to obesity management. The questions included 'What percentage of patients attending to your institution are overweight or obese?', 'In general, how well do you think patients understand overweight and 
Table 1 Sociodemographic characteristics of FGD participants

\begin{tabular}{lc}
\hline Characteristics & $\begin{array}{l}\text { Participants (n=22) } \\
\mathbf{n}(\%)\end{array}$ \\
\hline Age group & $10(45.5)$ \\
\hline $20-39$ & $10(45.5)$ \\
$40-59$ & $2(9.0)$ \\
\hline$>60$ & \\
Gender & $10(45.5)$ \\
\hline Male & $12(54.5)$ \\
\hline Female & \\
\hline Ethnicity & $19(86.3)$ \\
\hline Newar & $3(13.6)$ \\
\hline Brahmin & \\
Marital status & $15(68.2)$ \\
\hline Married & $6(27.3)$ \\
\hline Not married & $1(4.5)$ \\
\hline Widow & \\
\hline Education & $3(13.6)$ \\
\hline No formal education & $2(9.1)$ \\
\hline Primary level education & $6(27.3)$ \\
\hline Secondary level & $11(50.0)$ \\
\hline High school or more & \\
\hline Occupation & $3(13.6)$ \\
\hline Employed & $9(40.9)$ \\
\hline Self-employed & $4(18.2)$ \\
\hline Homemakers & $2(9.1)$ \\
\hline Unemployed & $4(18.2)$ \\
\hline Student & \\
\hline BMl & $9(40.9)$ \\
\hline$<25 \mathrm{~kg} / \mathrm{m}^{2}$ & $6(27.3)$ \\
\hline$\geq 25-29$ kg/m ${ }^{2}$ & $7(31.8)$ \\
\hline$\geq 30 \mathrm{~kg} / \mathrm{m}^{2}$ & \\
\hline Self-employed & \\
\hline
\end{tabular}

*Self-employed includes business and agriculture. $\mathrm{BMI}$, body mass index.

obesity?', 'How do community members view/perceive obesity?', 'Are there any common misconceptions in the community about obesity?', and 'What factors affect obesity management?' The moderator further probed on the above questions to explore further information.

\section{Data analysis}

FGDs and IDIs were recorded and transcribed verbatim in Nepali. SShrestha transcribed all recorded data. Data were analysed using the hybrid thematic analysis approach. ${ }^{21}$ We started with an 'a priori' list of codes drawn from the literature review and research questions and included additional codes that emerged during the inductive analysis process. ${ }^{22}$ One FGD and two interview transcripts were coded separately by two independent coders (SShrestha and SA) to enhance the data validity.
Coders discussed similarities and differences in the way codes were applied and agreed on the emerging codes. The interconnected codes were then grouped into subgroups and subgroups were further grouped into broad themes. After the discussion, the final codebook was updated. SShrestha further analysed the transcripts and grouped text units as per the codes using the Atlas.ti V.7. Selected quotes were reported.

\section{Ethics statement}

All participants who gave verbal consent to participate in the study also signed an informed consent form. Participation in the study was voluntary. All collected data were kept safe and strictly confidential.

\section{Patient and public involvement}

The study design and objectives were informed by previous findings from the DHS study, which indicated the high prevalence of obesity and poor cardiovascular health literacy among the community members. Although we did not specifically do separate community engagement for this study, we did include the discussions in the planning of the DHS in several community activities at schools, wards, meetings with female community health volunteers and other local community clubs.

\section{RESULTS}

\section{Characteristics of participants}

The characteristics of the FGD participants are presented in table 1.

We categorised themes derived from FGDs and IDIs into five categories: (1) burden of obesity; (2) knowledge of obesity; (3) attitude towards obesity; (4) body size perception; and (5) barriers to obesity management. The example of coding, categorising and formulating themes is given in table 2 .

\section{Burden of obesity}

Both FGD participants and HCPs identified obesity as a growing problem in the community. A medical officer stated that among the 20-25 patients he examines in a day, 7-8 of them are either overweight or obese. He further commented that while obesity might be increasing among teenagers, these teenagers are not under their radar as they seldom visit doctors.

Obesity was found to be higher among women and individuals aged 40 years and older in the community. Participants also pointed out that obesity is high among particular ethnic groups, such as Newar and Tamang, and among other subgroups such as married persons, office workers, housewives, businessmen, drivers, rich people and people living in urban areas.

In Newari culture, there are a lot of feasts and festivals, so they eat a lot. In the case of Tamang, they drink (alcohol) a lot. They eat much while drinking. Both are high in calories, so this might result in weight gain. (Nutritionist) 


\begin{tabular}{|c|c|c|c|c|}
\hline Codes & Definition of codes & Subcategory & Category & Theme \\
\hline Busy schedule & $\begin{array}{l}\text { Any reference to } \\
\text { discontinuing or not } \\
\text { initiating exercise due to } \\
\text { the patient's lack of time. }\end{array}$ & Exercise habit & $\begin{array}{l}\text { Challenges in behaviour } \\
\text { modification }\end{array}$ & $\begin{array}{l}\text { Barriers to weight } \\
\text { management }\end{array}$ \\
\hline Laziness & $\begin{array}{l}\text { Any reference to } \\
\text { discontinuing or not } \\
\text { initiating exercise due to } \\
\text { the patient's laziness. }\end{array}$ & & & \\
\hline Comorbidities & $\begin{array}{l}\text { Any reference to } \\
\text { discontinuing or not } \\
\text { initiating exercise due } \\
\text { to the patient's existing } \\
\text { disease/condition. }\end{array}$ & & & \\
\hline Lack of physical facilities & $\begin{array}{l}\text { Any reference to } \\
\text { discontinuing or not } \\
\text { initiating exercise due to } \\
\text { lack of physical facilities } \\
\text { and/or adequate space to } \\
\text { exercise. }\end{array}$ & & & \\
\hline Food taste & $\begin{array}{l}\text { Any reference to the } \\
\text { difficulty in modifying } \\
\text { dietary habits due to food } \\
\text { taste. }\end{array}$ & Food habit & & \\
\hline $\begin{array}{l}\text { Lack of access to healthy } \\
\text { food }\end{array}$ & $\begin{array}{l}\text { Any reference to the } \\
\text { difficulty in modifying } \\
\text { dietary habits due to the } \\
\text { inaccessibility of healthy } \\
\text { food. }\end{array}$ & & & \\
\hline
\end{tabular}

\section{Awareness of obesity}

Causes of obesity

All FGD participants believed that obesity could result from an unhealthy diet (eg, oily and fatty food), lack of exercise and sedentary lifestyles. Few mentioned heredity or old age as causes of overweight. Participants aged 40 and older reported they gained weight without any specific reasons while maintaining their diet.

In my case, I eat chapatti in the evening and rice in the morning. Still, my belly does not get decreased. In the past, despite my massive eating, I did not gain weight. Now, even drinking water leads to weight gain. (Male, above 40)
For some, it looks like genetics. Their grandparents are fat and so are the grandchildren. (Female, above 40)

Female participants further added the reasons for being obese, such as the use of family planning devices, an increase in food intake after childbirth and the habit of eating leftovers to prevent food waste.

(I) was told to eat more during my childbirth. Everyone used to say that I need more than before. So, the amount of my food increased. I used to eat less before (giggles). (Female, above 40 years) 
It's like, someone leaves the food, and instead of throwing, I feel like [I] should eat it. Why throw (food)? So, I gained weight. (Female, above 40 years)

\section{Complications of obesity}

Musculoskeletal problems, such as difficulty sitting and walking, back pain and pressure on the heel due to overweight were the predominant complications reported by participants. Many also reported high blood pressures, while few mentioned diabetes, high cholesterol and heart disease as complications. Participants' knowledge of complications was not only based on their experience but also on what they had seen in their family and community. Participants who had overweight were more concerned about complications, in terms of both their health and appearance, than those with a normal weight. Male participants under the age of 40 years were more concerned about their health and appearance due to overweight. One overweight male participant under 40 years stated he was ashamed of walking with his friends and added:

As per my experience, it is better to lose weight than to gain it. [...] Once I had an experience of being overweight. It was difficult. It's like I had Asthma [disease]. I could not walk. (Male, under 40 years)

Our body shape looks bad. [...] (We) look older ata younger age because of obesity. (Male, under 40 years)

HCPs, however, commented that people do not take obesity seriously because they lack adequate knowledge about its complications. Once HCP said:

Until and unless the disease does not get complicated, it barely comes to their mind that they should go for a check-up. Otherwise, they don't even give a try to reduce weight although they are asked to do so. (Medical officer)

Participants who feared the health consequences of obesity usually ask the HPs for suggestions to reduce weight. However, one HCP emphasised that the reason for being concerned is the appearance rather than disease.

I see these days that people are concerned with obesity not because of disease but because of how they look physically. There are very few who [are] concerned about disease. (Medical officer)

\section{Attitude towards obesity and overweight}

FGD participants reported that overweight was considered good in society, both health-wise and appearancewise. Some participants under 40 years also expressed their willingness to increase weight. One female participant described how odd it was to have a thin figure in her family:

...we are five daughters-in-law in the family...it looks odd when there is one thin person in the room... it does not match in the family. (Female, under 40 years)

For women, gaining weight after marriage was viewed positively.

If I lose my weight and visit there [maternal home], they [neighbors] would say that my husband did not provide me enough to eat [giggles]. If I go with my increased weight, they will say that my husband loves me. (Female, under 40 years)

However, participants also believed that too much weight gain (obesity) was perceived as bad in the community and that community perception/attitude towards obesity has been changing. Participants attributed this change to the information provided through media, such as television and radio, and to increasing obesity-related disease prevalence in the community.

...My mother-in-law used to say that if she saw any handsome and healthy person then she thought that the person belongs to high economic class. [...] She says it is good. However, nowadays, her view has changed. Now she says that it is not good to gain weight, and excess weight results in disease. (Female, under 40 years)

Most participants expressed a positive attitude towards thinness and expressed their willingness to lose weight. Those who had already faced problems or are currently facing problems due to obesity/overweight, both diseasewise and appearance-wise, did not want to increase their weight despite comments from their family and

If we, the overweight people, lose weight, we get comments (from others) like- what happened, what disease you suffered from, are you stressed, and all. But we have to take care of our own body although people comment. (Female, above 40 years)

HCPs also mentioned the low self-esteem and psychological stress they found among obese people, especially in teenagers, because of negative comments that people make about them.

It's like okay if someone [obese individuals] can take it easy when they are called fat ["Mote"]. Otherwise, what I also have seen among teenagers age 16-17 years is that they do not participate in dance [competitions]. They do not participate in game competitions because they think people will stare at them and flatter them. Such cases come often. (Nutritionist)

HCPs commented that though excessive weight (obesity) and thinness are considered bad in the community, overweight is still considered good. This concept is hard to change among people, even in educated people when it comes to children. The provider described saying,

(I have seen) a woman with a lean child. She cried after seeing another chubby baby by her side grieving 
what had happened to her children. That was a difficult time for me [to counsel her]. (Nutritionist)

\section{Body size perception}

Before carrying out the discussion, we measured the height and weight of each FGD participant. All participants aged 40 and above were found to be either obese or overweight. Nevertheless, when asked what they feel about body size, the majority of them perceived that their weight was normal.

It would be good if I could decrease my belly size. Otherwise, I feel like I am normal. (Male, under 40 years)

The majority of participants under 40 years had normal weight. Two participants, one male and one female, considered themselves overweight, although their measurement indicated normal weight.

Most participants perceived their body size and weight by measuring their clothes' size, evaluating themselves in mirrors, and experiencing others' comments about their body, while only a few male participants reported measuring their weight on a scale, when possible. However, HCPs reported that the number of people who are aware of and/or interested in measuring their weight is increasing in the community. As one said,

If we remember those people who measured their weight, the count will be double than our patients.

(Auxiliary health worker)

\section{Barriers to weight management}

\section{Challenges in behaviour modification}

Physical activity

All FGD participants mentioned that diet modification and exercise are keys to prevent and control obesity. However, only a few of the participants reported exercising to maintain or reduce their weight. Both overweight or obese and normal-weight participants reported similar barriers to weight management. The most commonly reported barriers were busy schedule and laziness followed by cold weather and lack of space or physical facilities for exercise. Participants above 40 years of age reported that comorbidities such as musculoskeletal pain limit their level of physical activity.

I cannot go [for exercise]. Otherwise, I want to walk. It is difficult for me to walk, my leg aches. (Female, above 40 years)

I don't have friends to walk together with. Here is no place for Yoga. [...]. I also need to manage time at home. (Female, under 40 years)

Two female participants under 40 years of age reported that they feel normal and thus do not feel a need to exercise.

We will exercise if we need to. Otherwise, it (the life) is going on. So, I feel- why should I exercise? (Female, under 40 years)
Participants had a diverse opinion on the adequate level of physical activity. A few believed that household chores like cooking and washing clothes were adequate for exercise, while others thought that exercise was only adequate when they sweat. Participants' required duration of exercise ranged from $10 \mathrm{~min}$ to 3 hours a day.

\section{Effect of challenging food environment and diet behaviour}

The most frequently reported barrier for diet control was difficulty in changing food habits due to food taste and desire to eat. Participants also mentioned the unavailability of healthy food due to the use of excessive pesticides in vegetables and fruits. In addition, participants reported that the increased availability and efficiency of consuming junk food has limited their consumption of healthier food. Consuming junk food was also a status symbol. One participant explained that people in the community eat junk food to show that they belong to a higher social status.

If our children walk taking the juice bottles and drinking juices, then that reflects a higher status. But, if they walk eating homemade popcorn, then that reflects the lower status. (Male, under 40 years)

\section{Lack of HCP's knowledge and anthropometric measurement tools}

HCPs reported that overweight and obesity were identified by measuring a patient's weight and height, by observation and by the patient's complaint. When asked specifically about measuring central obesity, the HCPs at the tertiary level stated that they measure waist circumference (WC) only for those who are diabetic or have a metabolic syndrome. However, the HCPs at the peripheral level were not aware of measuring central obesity. One put it this way:

We have not done that (measured central obesity). We do not have an instrument. We also do not have such information. If we were given an instrument and the District Health Office directed us to do so or if we were given any training....we do everything based on our knowledge. We do not have anything extra. (Auxiliary health worker)

\section{Lack of counselling}

HCPs at the peripheral level counsel to patients for $7 \mathrm{~min}$ to half an hour depending on the patient's condition and the provider's available time. At the tertiary level, the nutritionist spends around half an hour to $45 \mathrm{~min}$ in counselling. However, the medical officer at the tertiary level could only provide a maximum of 5 min for counselling because of their time constraints and high daily patient volume. The medical officer mentioned that it would be helpful if they had additional assistance.

Yes, I think it's a time factor (for not counseling patients). And another, I think it is helpful if we get a helping hand. One will take a note when one measure (weight), it expedites the process. (Medical officer) 


\section{DISCUSSION}

This study explored the perception of obesity and overweight among Nepalese adults living in a suburban community. We found that participants had inadequate knowledge and misconceptions regarding obesity and had perceived overweight as normal, healthy and attractive. The adults above 40 years of age did not perceive themselves to be overweight or obese even when they were. Only a few participants reported exercising and controlling their diet to prevent obesity or manage their weight.

Obesity was perceived as a growing problem in the Dhulikhel community. A 2016 cross-sectional study by Shrestha $e t$ al reported the prevalence of overweight and obesity among DHS participants aged 18 years and older as $28.4 \%$ and $8.1 \%$, respectively. ${ }^{9}$ Similarly, the nationally conducted WHO STEPS survey in 2019 reported the prevalence of overweight and obesity among Nepalese adults aged $15-45$ years as $20 \%$ and $4.3 \%$, respectively. ${ }^{6}$ In our study, participants reported that obesity was mainly a problem among individuals who are 40 years of age and above, married persons, office workers, businessmen, retired individuals and housewives. A 2011 study among civil servants in Nepal reported that married participants were 7.5 times more likely to be overweight/obese than non-married. ${ }^{18}$ Additionally, the occupation was found to be related to being overweight/obese. Based on the above findings, it is important to design intervention programmes targeting these populations to prevent overweight and obesity.

Participants mainly linked the causes of obesity to personal factors, such as fatty diet and physical inactivity, which is similar to other studies conducted in Nepal, India, Malaysia, South Africa and Morocco. 817182324 Few of our participants reported heredity as a cause of obesity. This contrasts with the result from the previous study done among civil servants in Nepal, which found that an almost equal number of participants viewed 'fatty foods' or 'a genetic disorder' as a cause of obesity. ${ }^{18}$ In addition to personal factors, women in our study stressed social and medical factors such as marriage, childbirth, the habit of eating leftovers and the use of contraceptives as causes of obesity and overweight among women. In Nepalese society, gaining weight right after marriage is considered a good sign of a healthy relationship with a husband and in-laws. Culturally, Nepalese prefers to finish the food on the day that is cooked. As women are the last members of a household to eat, they are expected to consume all remaining food. Additionally, women's increased food consumption after childbirth is believed to increase milk production and improved milk quality, and the well-being of both mother and child. Findings from the study conducted in the Laayoune community of Morocco also reported sociocultural pressure as a factor for increasing weight among women. ${ }^{16}$ In contrast to our study, this study reported that single women also desired to gain weight to maintain an ideal cultural beauty. It is important to educate women of reproductive age about obesity risks to promote a healthier lifestyle.

Health and appearance are the key motives to lose weight. ${ }^{25}{ }^{26}$ Similar to findings from previous studies in South Africa and Morocco, participants in our study who were concerned about the consequences of obesity and their appearance were more willing to lose or maintain their current weight. ${ }^{87}$ However, it is important to consider if people are only concerned with their appearance because the weight loss for a transient period to appear fit and attractive, such as in social events, will not be sustainable, and the attempt to lose a lot of weight in a short duration of time can be hazardous.

In our study, almost all participants who were 40 years and older underestimated their body weight, although they all met the criteria of overweight and obese. This finding is similar to studies conducted in Tanzania, Cameroon and in the USA. ${ }^{112327}$ Additionally, studies have also reported variation in weight estimation by gender and age. ${ }^{828}$ A qualitative study in South Africa reported that the majority of overweight and obese female participants perceived themselves to be normal or moderately overweight, and chose the silhouettes that were smaller than their body size. ${ }^{8}$ A cross-sectional study in Morocco reported that more women than men underestimated their body weight and men 40 years of age and above were more likely to underestimate their weight compared with women in the same age group. ${ }^{27}$ Individuals who do not perceive themselves as overweight and obese are likely to gain more weight due to their lowrisk perception and unwillingness to lose weight. ${ }^{8} 1112$ The inability for our participants to accurately recognise their body weight status may prevent them from adopting healthy behaviours and increase their risk to obesity and its complications. Therefore, the community should be made aware of the importance of measuring their weight at intervals, and health facilities should also increase educational campaigns to improve community awareness.

In Nepal, a big belly is culturally accepted as a sign of prosperity. ${ }^{718}$ Participants' perception that overweight is considered good, healthy and attractive is consistent with other studies conducted in South Africa, Morocco and the USA. ${ }^{823}$ Most strikingly, this was frequently reported by women under 40 years of age. Research has shown that women may be more accepting of obesity than men, and thus have a less negative attitude towards obese individuals. ${ }^{29}$ However, further studies on the role of gender in weight-related acceptance are needed.

Although overweight is acceptable, participants have a negative attitude towards an obese person. This reflects the finding of several other studies, ${ }^{8152330}$ whereby obese individuals are viewed as lazy, heavy, unattractive and are perceived to have illnesses associated with obesity. Studies have also shown the consequences of others' negative attitudes among obese persons. ${ }^{8} 15182330$ For example, a study in Cameroon reported that overweight Caucasian and African-American women were viewed differently and were discriminated against despite their 
hard work. ${ }^{23}$ Such internalised stigma among obese individuals is particularly from the belief that obesity is a result of an individual's failure to maintain a healthy lifestyle. ${ }^{15}$ Considering the fact that participants in our study primarily pointed out the internal factors such as diet and exercise, as causes of obesity, it is important to make people aware of sociocultural and medical factors to reduce obesity-related stigma and negative attitude. ${ }^{15}$ Further studies to explore the impact of negative attitudes on overweight or obese individuals in Nepal would be beneficial to develop intervention programmes in this setting.

Adequate exercise and a healthy diet are keys to managing obesity and other chronic diseases. ${ }^{31}$ Although participants in our study were aware that a healthy lifestyle will benefit them, they did not implement it. This difference in knowledge and practice has been described in many studies. ${ }^{82-34}$ This could be due to low awareness of obesity complications. In our study, both the overweight and the normal-weight participants reported similar barriers to weight management. This could be because only a few participants in our study reported exercising or controlling a diet to reduce or prevent obesity. Moreover, participants who were overweight did not perceive themselves as overweight and did not feel the need to change their behaviour. The cultural acceptance of overweight in Nepalese culture and the difficulties in modifying behaviour could be a challenge to implementing the effective intervention programme in this setting.

The surrounding environment influences our food choices and eating behaviour. ${ }^{35}$ Studies have shown a positive relationship between easy access to fast food and its high consumption, leading to obesity and other cardiovascular diseases. ${ }^{3637}$ Participants in our study also reported the increased availability of junk food as a cause of obesity. Interestingly, few participants in our study related junk food with a higher social status. This might be due to the influence of appealing advertisements and the increasing adoption of Western food, such as fries and chips in Nepal. A study conducted among school children in urban Nepal reported that children belonging to families with higher income were 1.7 times more likely to consume junk food than those belonging to families with lower income. ${ }^{38}$ Whereas, few other studies on school children showed no relationship between family income and junk food consumption. ${ }^{39} 40$ In addition, a cross-sectional study conducted among the DHS participants in 2016 reported no association between income status and fast-food consumption. ${ }^{41}$ Therefore, further studies exploring the relationship between socioeconomic status and junk food consumption are warranted in Nepal. In addition to junk food, our study participants also reported the use of pesticides in food as a barrier to healthy eating. In Nepal, pesticides are widely used in agriculture, especially in vegetable cropping. The pesticide's formulation and import increased by more than sixfold between 1997/1998 and 2011/2012. ${ }^{42}$ Kavrepalanchok, the district of Dhulikhel, is one of the highest pesticide user districts in Nepal. ${ }^{43}$ A study conducted among potato growers in Kavrepalanchok reported that approximately $94 \%$ of potato growers apply pesticides in potatoes. ${ }^{44}$ A qualitative study conducted among cafeteria managers in Dhulikhel Hospital reported the unavailability of healthy food in a local market as an obstacle to consuming healthy food in cafeterias. ${ }^{20}$ Most of the studies in Nepal are so far concentrated on modifying individual behaviours to prevent obesity. However, the above findings suggest that we need to direct our focus on the broader level, addressing the challenges associated with the food environment.

As in other LMICs, obesity is primarily assessed based on body mass index (BMI) in Nepal. ${ }^{15} 4546$ However, BMI cannot differentiate between weight because of excessive muscle percentage and body fat proportions. ${ }^{15}$ Studies have shown that people with normal BMI are at risk of cardiovascular diseases because of central obesity. ${ }^{15} 4546$ The prevalence of central obesity has been increasing among South Asians. A 2006 study in Nepal reported a higher prevalence of central obesity than general obesity among the study population in Dharan. ${ }^{47}$ Similarly, a study in China reported that the prevalence of central obesity among adults with BMI $<25 \mathrm{~kg} / \mathrm{m}^{2}$ increased by almost twofold from $11.9 \%$ in 1993 to $21.1 \%$ in $2009 .{ }^{46}$ If the study did not consider measuring WC for obesity, they would have missed $65 \%$ of the cases. This highlights the importance of measuring WC to accurately measure obesity in clinical settings.

This study is the first qualitative study in Nepal that aimed to understand the perception of obesity among adults in a suburban community from both community and HCPs' perspectives. The use of open-ended questions provided insights into participants' perspectives and lived experiences. However, several limitations exist. This study is confined to the suburban area; therefore, the perception of urban and rural areas is under-represented. However, a qualitative study is intended to understand a phenomenon, and not to analyse the relationship between variables. ${ }^{3348}$ All the FGD participants belonged to the Hindu religion; therefore, the study could not explore the perception of individuals of other religions. However, the majority of the population in this area are Hindu. Although few numbers of HPs were interviewed in this study, we have considered to include them from the different healthcare levels. Given these limitations, however, the study provides profound information on the community's perception of obesity in Nepal.

\section{CONCLUSIONS}

This qualitative study explored the knowledge, attitude and perception of obesity among Nepalese adults in a suburban community. Given the participants' misconception and inadequate knowledge regarding obesity, and the underestimation of their body size, it is suggested to design and disseminate culturally appropriate health information to manage obesity in the community. Also, 
it is essential to consider challenges associated with food environment while designing health intervention. Our finding shows that the HCPs at the peripheral health institutions lack training and instrument to measure central obesity. Since the prevalence of central obesity is rising in South Asians, including the Nepalese population, it is important to consider central obesity while training health workers at the peripheral level.

AcknowledgmentsThis study was supported by grants from the Wide Open Vistas, USA. We acknowledge the support of Dhulikhel Hospital for allowing us to conduct this study. We also thank all participants for providing their invaluable contribution to the study.

Contributors SShrestha, the principal investigator, conceived the study, transcribed and analysed data, and developed the manuscript. BMK and RK contributed to the research design. SA contributed to collecting and analysing the data. SSubedi contributed to revising the manuscript. All authors read and approved the final manuscript for publication.

Funding This work was supported by the Wide Open Vistas (grant number WOV-002).

Competing interests None declared.

Patient consent for publication Not required.

Ethics approval Ethical approval was obtained from the Kathmandu University School of Medical Sciences Institutional Review Committee (IRB\# 36/16).

Provenance and peer review Not commissioned; externally peer reviewed. Data availability statement № data are available.

Open access This is an open access article distributed in accordance with the Creative Commons Attribution Non Commercial (CC BY-NC 4.0) license, which permits others to distribute, remix, adapt, build upon this work non-commercially, and license their derivative works on different terms, provided the original work is properly cited, appropriate credit is given, any changes made indicated, and the use is non-commercial. See: http://creativecommons.org/licenses/by-nc/4.0/.

ORCID iD

Sachita Shrestha http://orcid.org/0000-0001-7878-8756

\section{REFERENCES}

1 World Health Organization. Global health risks : mortality and burden of disease attributable to selected major risks, 2009. Available: https://apps.who.int/iris/handle/10665/44203

2 Zalesin KC, Franklin BA, Miller WM, et al. Impact of obesity on cardiovascular disease. Med Clin North Am 2011;95:919-37.

3 Colditz GA, Willett WC, Stampfer MJ, et al. Weight as a risk factor for clinical diabetes in women. Am J Epidemiol 1990;132:501-13.

4 Colditz GA, Willett WC, Rotnitzky A, et al. Weight gain as a risk factor for clinical diabetes mellitus in women. Ann Intern Med 1995;122:481-6.

5 Yoon K-H, Lee J-H, Kim J-W, et al. Epidemic obesity and type 2 diabetes in Asia. Lancet 2006;368:1681-8.

6 Dhimal M, Bista B, Bhattarai S. Report of non communicable disease risk factors: steps survey Nepal 2019. Kathmandu, 2020.

7 Vaidya A, Shakya S, Krettek A. Obesity prevalence in Nepal: public health challenges in a low-income nation during an alarming worldwide trend. Int J Environ Res Public Health 2010;7:2726-44.

8 Okop KJ, Mukumbang FC, Mathole T, et al. Perceptions of body size, obesity threat and the willingness to lose weight among black South African adults: a qualitative study. BMC Public Health 2016;16:365.

9 Shrestha A, Koju RP, Beresford SAA, et al. Reproducibility and relative validity of food group intake in a food frequency questionnaire developed for Nepalese diet. Int J Food Sci Nutr 2017;68:605-12.

10 Mishra SR, Neupane D, Bhandari PM, et al. Burgeoning burden of non-communicable diseases in Nepal: a scoping review. Global Health 2015;11:32.

11 Muhihi AJ, Njelekela MA, Mpembeni R, et al. Obesity, overweight, and perceptions about body weight among middle-aged adults in Dar ES Salaam, Tanzania. ISRN Obes 2012;2012:1-6.
12 Awah PK, Kengne AP, Fezeu LLK, et al. Perceived risk factors of cardiovascular diseases and diabetes in Cameroon. Health Educ Res 2008;23:612-20.

13 Mellor D, Fuller-Tyszkiewicz M, McCabe MP, et al. Body image and self-esteem across age and gender: a short-term longitudinal study. Sex Roles 2010;63:672-81.

14 Koju RP, Karmacharya BM, Shrestha A, et al. Design of the Dhulikhel heart study (DHS): the epidemiology of emerging cardiovascular disease in Nepal. Ann Glob Health 2014;80:204-5.

15 Sikorski C, Riedel C, Luppa M, et al. Perception of overweight and obesity from different angles: a qualitative study. Scand J Public Health 2012;40:271-7.

16 Rguibi M, Belahsen R. Body size preferences and sociocultural influences on attitudes towards obesity among Moroccan Sahraoui women. Body Image 2006;3:395-400.

17 Agrawal P, Gupta K, Mishra V, et al. A study on body-weight perception, future intention and weight-management behaviour among normal-weight, overweight and obese women in India. Public Health Nutr 2014;17:884-95.

18 Simkhada P, Poobalan A, Simkhada PP, et al. Knowledge, attitude, and prevalence of overweight and obesity among civil servants in Nepal. Asia Pac J Public Health 2011;23:507-17.

19 Oli N, Vaidya A, Subedi M, et al. Diet and physical activity for children's health: a qualitative study of Nepalese mothers' perceptions. BMJ Open 2015;5:e008197.

20 Tamrakar D, Shrestha A, Rai A, et al. Drivers of healthy eating in a workplace in Nepal: a qualitative study. BMJ Open 2020;10:e031404

21 Swain J. A hybrid approach to thematic analysis in qualitative research: using a practical example. SAGE Publications Ltd, 2018.

22 Braun V, Clarke V, Cooper H. Apa Handbook of research methods in psychology. 2, 2012.

23 Blixen CE, Singh A, Thacker $\mathrm{H}$. Values and beliefs about obesity and weight reduction among African American and Caucasian women. $J$ Transcult Nurs 2006;17:290-7.

24 Chang CT, Chang KH, Cheah WL. Adults' perceptions of being overweight or obese: a focus group study. Asia Pac J Clin Nutr 2009;18:257-64.

25 Cheskin LJ, Donze LF. msJAMA: appearance vs health as motivators for weight loss. JAMA 2001;286:2160.

26 Teixeira PJ, Silva MN, Mata J, et al. Motivation, self-determination, and long-term weight control. Int J Behav Nutr Phys Act 2012;9:22

27 Lahmam A, Baali A, Hilali MK, et al. Obesity, overweight and bodyweight perception in a high atlas Moroccan population. Obes Rev 2008;9:93-9.

28 Greener J, Douglas F, van Teijlingen E. More of the same? conflicting perspectives of obesity causation and intervention amongst overweight people, health professionals and policy makers. Soc Sci Med 2010;70:1042-9.

29 Pantenburg B, Sikorski C, Luppa M, et al. Medical students' attitudes towards overweight and obesity. PLoS One 2012;7:e48113.

30 Cossrow NH, Jeffery RW, McGuire MT. Understanding weight stigmatization: a focus group study. J Nutr Educ 2001;33:208-14.

31 Ard JD, Svetkey LP. Diet and blood pressure: applying the evidence to clinical practice. Am Heart J 2005;149:804-12.

32 Risso-Gill I, Balabanova D, Majid F, et al. Understanding the modifiable health systems barriers to hypertension management in Malaysia: a multi-method health systems appraisal approach. BMC Health Serv Res 2015;15:254.

33 Mothiba T, Malema R, Lekhuleni M. The experiences of the newly diagnosed hypertensive patients admitted into tertiary hospital campus in Limpopo Province, South Africa. Afr J Phys Health Educ Recreat Dance 2013:213-21.

34 Shrestha S, Shrestha A, Koju RP, et al. Barriers and facilitators to treatment among patients with newly diagnosed hypertension in Nepal. Heart Asia 2018;10:e011047.

35 Lake AA. Neighbourhood food environments: food choice, foodscapes and planning for health. Proc Nutr Soc 2018;77:239-46.

36 Mohammadbeigi A, Asgarian A, Moshir E, et al. Fast food consumption and overweight/obesity prevalence in students and its association with general and abdominal obesity. J Prev Med Hyg 2018;59:E236.

37 Mistry SK, Puthussery S. Risk factors of overweight and obesity in childhood and adolescence in South Asian countries: a systematic review of the evidence. Public Health 2015;129:200-9.

38 Karki A, Shrestha A, Subedi N. Prevalence and associated factors of childhood overweight/obesity among primary school children in urban Nepal. BMC Public Health 2019;19:1055.

39 Poudel B, Tiraphat S, Hong SA. Factors associated with junk food consumption among urban school students in Kathmandu district of Nepal. J Public Health Dev 2018;16:59-72. 
40 Upreti YR, Bastien S, Bjonness B, et al. Socio-Ecological factors associated with snacking behaviors of basic school students in Nepal. Curr Res Nutr Food Sci 2020;8:774-84.

41 Shrestha A, Koju RP, Beresford SAA, et al. Food patterns measured by principal component analysis and obesity in the Nepalese adult. Heart Asia 2016;8:46-53.

42 Sushma D, Dipesh R, Lekhendra T. A review on status of pesticides use in Nepal. Res J Agri Forestry Sci 2015;2320:6063.

43 Yubak Dhoj G. Status of pesticide use in Nepal and future strategy for their safe and alternative uses, 2016.

44 Sapkota KR, Sapkota S, Sapkota S, et al. Pesticides handling practices among potato growers in Kavrepalanchok, Nepal. J Agric Nat Resour 2020;3:77-87.
45 Poobalan A, Aucott L. Obesity among young adults in developing countries: a systematic overview. Curr Obes Rep 2016;5:2-13.

46 Du T, Sun X, Yin P, et al. Increasing trends in central obesity among Chinese adults with normal body mass index, 1993-2009. BMC Public Health 2013;13:327.

47 Vaidya AK, Pokharel PK, Nagesh S, et al. Association of obesity and physical activity in adult males of Dharan, Nepal. Kathmandu Univ Med J 2006;4:192-7.

48 Shrestha S. Barriers and facilitators to treatment among newly diagnosed hypertensive patients in Nepal: a qualitative study, 2016. 